\title{
Risk Analysis of IT Outsourcing Case Study on Public Companies in Thailand
}

\author{
Thanapol Ongwattanasirikul, Settapong Malisuwan, and Navneet Madan
}

\begin{abstract}
IT outsourcing is the subcontracting of previous in-house IT activities to external IT vendors who can do them better and more efficiently because they possess more resources and higher experatise. Firms are driven to acquire IT outsourcing services because they expect these specialized firms to provide efficient services which lead to cost saving and increase in profit. However, only half of IT outsourcing contracts has delivered results as promised. In this research a conceptual framework is presented and tested to reveal the relationship between IT outsourcing risk factors and negative outcomes that occur from IT outsourcing. The result concluded that four risk factors "Measurement problem", "Lack of expertise of vendor with outsourced activity", "Uncertainty", and "Interdependence of activities", are significant predictors of negative outcomes in Thailand. The other risk factors which are "Lack of expertise of client with outsourced activity", "Lack of expertise of client with outsourcing contract", "Lack of expertise of vendor with outsourcing contract", "Asset specificity", and "Small number of vendors" do not have a significant relationship with negative outcomes. Finally, this research also provides several major recommendations that IT outsourcers must acknowledge and implement in order to manage IT outsourcing risks and get the most benefit from IT outsourcing as possible.
\end{abstract}

Index Terms-Agency theory, IT outsourcing, IT outsourcing risks, negative outcomes, transaction cost theory.

\section{INTRODUCTION}

IT outsourcing, "the use of outside contractors or external organizations to acquire IT services," has experienced strong growth in the recent years [1]. This trend, which includes the increasing of scope and range of IT outsourcing services, has become a global trend.

Nevertheless, many organizations are discontented with quality of service provided by their IT outsourcing. IT outsourcing vendors failed to meet service level or cost saving required by the client. Nearly seventy percent of organizations outsourcing their IT functions said that they are dissatisfied with service provided by their vendors. Numerous researches revealed that only half of IT outsourcing contracts delivered promised cost saving of twenty to thirty percent [2].

These failures show that there are various types of risks associated with IT outsourcing. Majority of IT outsourcing

Manuscript received January 9, 2013; revised April 10, 2013. Financial support for this research paper is provided by National Broadcasting and Telecommunications Commission, Bangkok, Thailand.

T. Ongwattanasirikul is wih Siemens Group, Bangkok, Thailand (e-mail: thanapol.ong@gmail.com).

S.Malisuwan and N. K. Madan are with National Broadcasting and Telecommunications Commission Bangkok, Thailand (e-mail: settapong.m@nbtc.go.th,navneet.nbtc@gmail.com). risks can be described by using Agency theory and Transaction Cost theory [3], [4]. They identified various types of risks which are additional costs, service debasement, disputes and litigation.

Without a thorough comprehension of how to manage these risks, any benefits achieved could be offset by significant losses. Therefore, risks must be measured, understood and then mitigated to ascertain that organizations will meet their IT outsourcing goals. Organizations that perform risk analysis and correctly manage risks associated with IT outsourcing will be able to anticipate and alleviate issues associated with IT outsourcing [3].

Established literatures in IT outsourcing provides strong evidence that IT-outsourcing risk management has a significant role in determining the success or failure of IT management. If risks including the relationship between undesirable outcomes and factors leading to outcomes can be understood, then they can be managed more effectively and efficiently. Consequently, organizations will be able to harvest as much benefit as it can out of IT outsourcing.

\section{LITERATURE REVIEW}

To increase comprehension on IT outsourcing risks, numerous lead researchers have highlighted two leading theories namely, Agency Theory and Transaction Cost Theory

\section{A. Agency Theory}

Agency theory offers foundation about the relationship between the vendor and client, and the incentive of the vendor and client to implement IT outsourcing services. Opportunism can be defined as the tendency to deceive clients in order to reap high benefit. Opportunism is expected to occur in relationships where there is an agent (or vendor) and a principal (or client). Vendors adopt opportunistic behavior for its own benefit whenever the chance arises [2]. Moral, social norms, the risk of prosecution and damage of reputation mitigate the risk of opportunism to a certain extent but cannot prevent all opportunistic behaviors [5].

Opportunism mainly constitutes three manifestations, which are moral hazard, adverse selection and imperfect commitment [6]. Moral hazard occurs when it is not possible for the client to scrutinize an IT outsourcing vendor's behavior without incurring additional costs. In cases where the client cannot detect poor performance, the IT outsource vendor can blame poor performance on factors beyond its control. Adverse selection occurs when the client cannot inspect the IT outsourcing vendor's characteristics. If the client fails to deal with adverse selection, the client will face difficulty in choosing a suitable vendor. Lastly, imperfect 
commitment refers to the inability of both the vendor and the client to fully commit to the business relationship [6].

\section{B. Transaction Cost Theory}

The transaction cost theory is based on two behavioral assumptions [7]. Firstly, the theory is based on the assumption of bounded rationality, which refers to incapability of the human mind in assessing all possible options for decision making because it has incomplete information of the situation or because of the cognitive limitation of their mind. In the context of outsourcing, bounded rationality occurs when clients have incomplete knowledge and skills to evaluate appropriate vendors, evaluate correct or standard requirement, and lastly, its inability to correctly manage its relationship with the vendor. Secondly, this theory is dependent on its assumption on opportunism, where it is assumed that people are likely to be deceiving and will act on the basis of personal gain. These two behavioral assumptions are certainly relevant in the IT outsourcing context [4].

\section{Factors Leading to Negative Outcomes}

Based on these two theories, the risk factors are identified and are classified into three factors which are client factor, transaction factor and uncertainty. Client factor is composed of "Lack of expertise of client with outsourced activity", and "Lack of expertise of client with outsourcing contract". Vendor factor is composed of "Lack of expertise of vendor with outsourced activity" and "Lack of expertise of vendor with outsourcing contract". Transaction Factor is composed of "Asset specificity", "Interdependence of activities", "Measurement problems", "Small number of vendors", and "Uncertainty".

\section{Client Factor}

Lack of experience and expertise of client with outsourced activity: Expertise is a special skill or knowledge that is acquired by studying, training, or practicing [8]. The term expertise can be used interchangeably with experience [9]. From the literature review, the lack of experience or expertise of the client with outsourced activity is a major risk factor that leads to negative outcomes such as declining service level, hidden costs and loss of control over costs [10]-[12].

Lack of experience and expertise of client with outsourcing contract: The client's lack of expertise to manage outsourcing contract is another risk factor because the client may underestimate transition and management costs. This would result in the client being vulnerable to the vendor's opportunistic behavior [10]. This inexperience can lead to disputes and litigation with the vendor, declining service level and escalating service costs [13].

\section{E. Vendor Factor}

Lack of experience and expertise of vendor with outsourced activity: A vendor is likely to exaggerate the expertise it possesses [10]. Moreover, a vendor may not be able to respond to rapid changes in business environment or technological advancements. In other cases, the vendor may not fully comprehend the nature of the client's business, its objectives or expertise required to fulfill the client's business goals $[10,13]$. If the vendor does not have sufficient skills, clients will experience low service quality which will lead to increased costs, and target performance will be suboptimal [11]. Consequently, this may lead to dispute and litigation over the service rendered [10].

Lack of experience and expertise of vendor with outsourcing contract: A vendor who possesses expertise in outsourcing contract is perhaps good in reaping more benefits than an inexperienced one during the process of contract negotiation [4]. Conversely, an ineffectual vendor is unlikely to bargain much during the negotiation and may end up with signing clauses that will give rise to disputes and litigations in the future [10]. This may include but not limited to agreeing to clauses such as benchmarked costs conducted by an independent organization without the right to agree on the methodology, source data and sample selection [4].

\section{F. Transaction Factor}

Asset Specificity: Asset specificity "is the degree to which an asset can be redeployed without sacrificing its productive value if the contract is to be interrupted or prematurely terminated" [7]. Since the "next best use" of the asset will result in lower value than the value that could be earned from its original intended transaction, the investor would lose part of its investment if the original transaction was not accomplished. This could result in a situation where the vendor who has not invested its resources could reap benefits from the client by intimidating the client into a lock-in situation by threatening to withdraw from the transaction [14]-[16]. Moreover, the vendor may also use its investment into the relationship as a reason to increase its bargaining power and intimidate the client in the event of the contract renewal.

Interdependence of activities: Interdependence of activities is when the efficiency of one business task, activity or function depends on the successful implementation of other business tasks, activities or functions [17, 18]. This interdependence of the business functions will negatively impact business performance because it causes organizational inflexibility where the organization is not able to effectively respond to rapid business environment changes. The more the interdependence of the business activities there will be higher need for coordination between the client and the vendor. This makes mutual problem solving even more critical and if mutual problem solving fails it may hinder cost control [19].

Measurement problems: The accurateness with which buyers measure the quality of products and services they purchase determines its effectiveness in responding to rapid business environment changes. If buyers do not have an accurate measurement tool to analyze quality of products and services, buyers will have to employ a thorough or manual product/service monitoring method which is a costly process [20]. Additionally, if performance cannot be easily evaluated, our capability in responding to benchmark of the market maybe inefficient and the client will not know how to reward IT outsourcing vendors and how to evaluate their performance [7]. Therefore, the ability to measure outcomes with ease is critical to the overall performance of the firm in market.

Small number of vendors: Number of vendors refers to the degree to which a client has reputable and credible choices of vendors to meet its demands [21]. A limited number of 
vendors may cause the lock-in problem because the bargaining power of vendors increases as their number of vendor decreases. This lack of alternative vendors to choose from causes a client's over dependency on its vendor. Over dependency of clients on vendors is likely to motivate opportunistic behavior from vendors, hence resulting in escalating transaction costs [10].

Uncertainty: Uncertainty refers to the volatility in the business environment which results in failure of firms in anticipating and responding to market changes. Since this phenomenon is hard to anticipate, it is impossible to write uncertainty clauses in the contract in specific terms [22]. Therefore, an increase in uncertainty can motivate the vendor to allege in opportunistic behavior when contract clause needs to be amended [7].

There are two types of uncertainty: environmental uncertainty and technological discontinuity [23]. To begin with, environmental uncertainty refers to rapidity of market and demand change in combination with bound rationality which decreases the ability of IT outsourcing vendor and client to plan effectively. This leads to contractual amendments resulting in transaction costs [24].

The second uncertainty, technological discontinuity, refers to technological change or radical innovation that may cause the technology within the original contract to be outdated. This breakthrough may cause the parties to amend their contract resulting in transaction costs from contractual amendments [10, 11].

\section{G. Negative Outcomes}

The previously described risk factors can lead to the negative outcomes. Negative outcomes can be categorized into several types which are "Unexpected Transition and Management Costs", "Increased costs of services", "Costly Contractual Amendments", "Lock-in", "Service Debasement", and "Disputes and Litigation."

Unexpected Transition and Management Costs: Transition costs comprises of setup costs, redeployment or relocation costs and many more. Management costs comprises of costs relating to human resources costs that incur from managing an outsourcing contract, searching, evaluating and selection of suitable vendor, benchmark vendor services according to that of industry, indicating the legal terms required in contract, costs of negotiation and dissolving dispute between client and vendor, and many more $[4,10]$.

Increased costs of services: Increased costs of services result from vendor's opportunistic behavior. The vendor may charge too much for its services in order to reap higher profit from the client [10]. In addition, this includes costs that the client assume are included in the contract but, in fact are not. For instance, costs of personal-computer support, rewiring for office moves or even simple consultations about which equipment to purchase [12], [25].

Costly Contractual Amendments: In case that client needs change or it is discovered that contract is incomplete because certain essential clauses are missing, the contract needs to be amended. However, many vendors often overcharge their clients for new services or any alteration of existing services [11], [25]. "Costly contractual amendments may result from any alterations, redrafting or changes made at any time during the contract to parts of the contract or all of its clauses whenever a contractual party (the client and/or IT vendor) considers it is necessary" [4].

Lock-in: When the time for contract renewal arrives, a disgruntled client may want to change vendor. Nevertheless, there may be difficulties in attempting to do so. For instance; there is a risk that the client's required assets and client's personnel who has expertise in conducting outsourced activity may be transferred to the vendor. This could make repatriation very costly or impossible [6]. Alternatively, in case the client may want to transfer the service from one vendor to another vendor, difficulty could arise if there are limited quality vendors in the market.

Service Debasement: Service debasement is any decrease in the quality of services provided to a client such as "poor response time, poor turnaround time, late updates of software, applications which do not meet the requirements", etc [10].

Disputes and Litigation: Dispute and litigation is defined as controversy relating to the association or representation of the contracting parties in negotiating, fixing, maintaining, changing or seeking to arrange the terms or conditions of a contract and the process of bringing and pursuing a lawsuit [26]. Disputes and litigation are costly due to the costs of consultation, lawyers, and or any cost incurring from in-house resources in spending their time working on the litigation and the indirect costs, in order to mitigate negative effects on reputation [4].

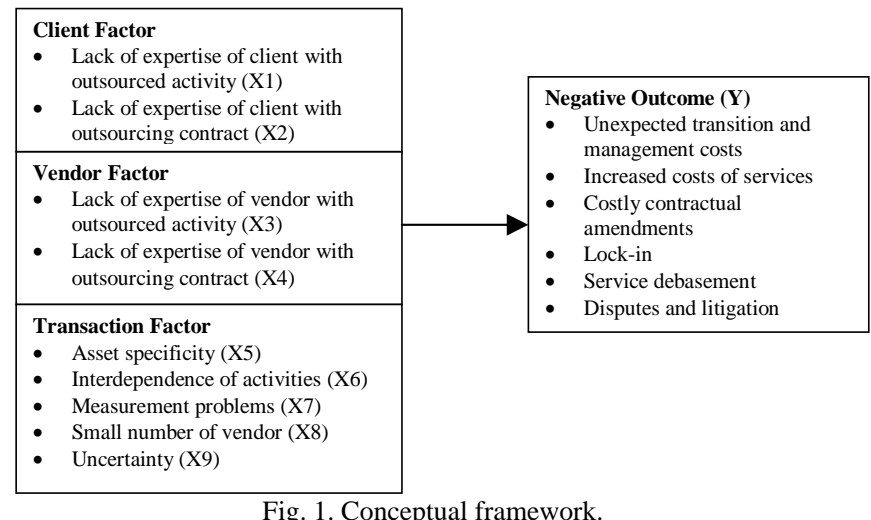

\section{RESEARCH FRAMEWORK AND METHODOLOGY}

\section{A. Research Hypothesis}

This research was conducted based on the objective, which was to study the relationship between risk factors and the negative outcomes of IT outsourcing. Thus, these nine hypotheses were established.

\section{H1: $X 1$ significantly affects $Y$}

\section{H2: $X 2$ significantly affects $Y$}

H3: $X 3$ significantly affects $Y \ldots$

\section{H9: $X 9$ significantly affects $Y$}

This is a descriptive research which investigates and explains the characteristics of a group of interesting variables. The research also includes the hypotheses testing in order to offer an enhanced understanding of the cause-and-effect relationships existing among variables. Survey is used in this study because survey is an effective tool to get opinions, attitudes and descriptions as well as to gain insights on 
cause-and-effect relationships. The questionnaires were sent to the target population of this research, the public companies, which consisted of 524 companies (from The Stock Exchange of Thailand (SET) as of 5th April 2010).

\section{B. Conceptual Framework}

This part has been adapted from the research in literature review and is presented in Fig. 1. This research comprises of nine independent variables categorized into three factors: client factor, vendor factor, and transaction factors which impact dependent variable, negative outcomes.

\section{DATA ANALYSIS AND RESUltS}

The SPSS Program's reliability calculation has found that the Cronbach alpha from the pretest is higher than 0.7 which is acceptable to establish scale's reliability [27]. The response rate is acceptable in comparison to the similar type of mail surveys.

\section{A. Sample Characteristics}

More than half of the returned questionnaires were answered by IT managers which is the target sample as shown in TABLE I. The respondents are mostly in the industrial sector, followed by property and construction sector, and financial sector which reflects the population characteristics of companies in Thailand as shown in TABLE II. Outsourced activity percentage is highest for website/e-commerce followed by ERP and network operations as seen in Table III. Majority of companies surveyed conduct IT outsourcing with at least three vendors. Software development is the most popular.

TABLE I: PERCENT OF RESPONSES BY POSITION

\begin{tabular}{ll}
\hline \hline \multicolumn{2}{c}{ TABLE I: PERCENT OF RESPONSES BY POSITION } \\
\hline Position & Percent of questionnaires \\
\hline CIO or IT Executive & 8.7 \\
IT Manager & 57.5 \\
Others & 31.6 \\
\hline Total & $\mathbf{9 7 . 8}$ \\
\hline Not Valid & 2.2 \\
\hline Total (valid+non valid) & $\mathbf{1 0 0 . 0}$ \\
\hline \hline
\end{tabular}

TABLE II: PERCENT OF OUTSOURCING COMPANIES BY INDUSTRY

\begin{tabular}{ll}
\hline Industry sector & $\begin{array}{l}\text { Percent of total outsourcing } \\
\text { companies }\end{array}$ \\
\hline Resource & 5.56 \\
Financial & 18.75 \\
Service & 6.25 \\
Property and Construction & 17.36 \\
Technology & 5.56 \\
Industrials & 20.83 \\
AgroandFood & 6.25 \\
Consumer & 4.17 \\
Others & 11.81 \\
\hline Total & $\mathbf{9 6 . 5 3}$ \\
\hline Not valid & 3.47 \\
\hline Total (valid + not valid) & $\mathbf{1 0 0}$ \\
\hline \hline
\end{tabular}

TABLE III: PERCENT OF COMPANIES BY OUTSOURCED ACTIVITY

\begin{tabular}{ll}
\hline \hline Outsourced activity & Percentage of total \\
\hline Data Center Operations & 4.14 \\
Data Warehousing & 2.66 \\
Desktop Management & 3.85 \\
Disaster Recovery Services & 5.03 \\
ERP & 12.13 \\
Help Desk & 6.51 \\
Hosted Applications & 6.51 \\
Network Operations & 11.24 \\
Software Development & 23.08 \\
Website/E-Commerce & 21.01 \\
\hline Others & 3.85 \\
\hline Total & $\mathbf{1 0 0}$ \\
\hline
\end{tabular}

SPSS automatically chooses the significant independent variables in stepwise method. IN "Lack of expertise of vendor with outsourced activity"," Interdependence of activities", "Measurement problems", and "Uncertainty" statistically affect negative outcomes significantly at 0.05 level whereas other variables do not. The results also reveal that "Measurement problems" has the most significant impact on negative outcomes followed by "Lack of expertise of vendor with outsourced activity", "Uncertainty", and "Interdependence of activities" respectively. The result of regression analysis is shown in Table IV.

TABLE IV: REGRESSION ANALYSIS

\begin{tabular}{|c|c|c|c|c|c|}
\hline \multirow[t]{2}{*}{ Model } & \multicolumn{2}{|c|}{ Unstandardized Coefficients } & \multirow{2}{*}{$\begin{array}{l}\text { Standardized } \\
\text { Coefficients } \\
\text { Beta }\end{array}$} & \multirow[t]{2}{*}{$\mathbf{T}$} & \multirow[t]{2}{*}{ Sig. } \\
\hline & $\mathrm{B}$ & Std. Error & & & \\
\hline (Constant) & .312 & .410 & & .761 & .448 \\
\hline $\begin{array}{l}\text { Lack of expertise of vendor with } \\
\text { outsourced activity }\end{array}$ & .267 & .084 & .237 & 3.176 & .002 \\
\hline Uncertainty & .182 & .067 & .212 & 2.715 & .008 \\
\hline
\end{tabular}

\section{B. The Factors Affecting Negative Outcomes}

Lack of expertise of vendor with outsourced activity: From the research results the lack of expertise of vendor with outsourced activity has a significant positive effect on negative outcomes. This means that the more incompetent (inexperienced) the vendor with the outsourced activity, the higher the negative outcomes. This lack of expertise will cause the low performance of vendor in managing outsourced activities. It will also increase cost and may lead to dispute and litigation.

Interdependence of activities: The findings from regression analysis reveal that the interdependence of activities has a significant positive impact on negative outcomes. Consequently, the higher the interdependence of outsourced activities, there is a higher likelihood of negative outcomes. This interdependence will cause higher costs in managing the transactions and low service quality due to inflexibility. This may also lead to disputes among parties. 
Measurement problems: Results revealed that measurement problems have a significant positive influence on negative outcomes. This means that the more the measurement problems, the more the negative outcomes. Measurement issues may lead to high cost of service, service debasement, dispute and litigation due to inability to monitor the transactions. If the company decides to outsource IT, it should have clear standards and measurement tools to evaluate the performance of the outsourcing service provider whether its performance is in line with the contract or not.

Uncertainty: Uncertainty has significant positive impact on negative outcomes. The higher the uncertainty there will be an increase in negative outcomes. In the uncertain environment, the inflexibility of the contract may cause costly contractual amendments. Moreover, the vendors may take advantage of the clients by construing vague clauses or clauses not mentioned in the contract to their own personal gain. To mitigate this uncertainty, a company should create proper procedures for decision making within the business relationship, hence leading to organization's ability to resolve issues in a timely and uncomplicated manner. Another method is increase of flexibility of the contract by shortening the contract period, flexibility in price adjustment, termination of the contract, etc. This is a possible solution as it leaves parts of a contract open for changes due to the varying circumstances [4].

The Factors with no Significant Effect on Negative Outcomes: The research results show that "Lack of expertise of client with outsourced activity", "Lack of expertise of client with outsourcing contract", "Lack of expertise of vendor with outsourcing contract", "Asset specificity", and "Small number of vendors" do not significantly affect the negative outcomes

Lack of expertise of client with outsourced activity and outsourcing contract: One reason for the insignificance can be due to the contracting experience of the responding industries. The respondents mostly come from industrial section, financial section, and property and construction section. They have much experience in writing contracts due to the nature of their businesses, which associated with many contracts, deals and agreements with other parties such as purchasing contracts, financial contracts, etc. Since the contracts in these sections contain high value of money and have complex details such as terms of agreements, number of participants, decision makers details and steps of negotiations, the companies have to ensure the terms in the contracts follows the acceptable standard. Sometimes it is vital to consult with external experts in order to protect the company's personal interest in order to harvest the most benefit that it can from the contract outcome. Thus, by having the contracting experience, these companies can apply it to deal with IT outsourcing vendors and reduce the risk from the outsourcing even if they are inexperience in IT outsourcing.

Lack of expertise of vendor with IT outsourcing contract: Lack of expertise of vendor with outsourcing contract is the only variable of vendor factors which does not have a significant impact on IT outsourcing negative outcomes. The reason may be the intention to compromise between the parties, client and vendor. The lack of expertise of vendor with the outsourcing contract can lead to incomplete contract which may result in litigation. Since the costs and fees of litigation are quite high and the time consumed in the process of prosecution is so long both parties are likely to compromise rather than to bring the case to court. If a case is brought to the court, it is likely to take at least one to two years on average to finish each case. This long period is due to various reasons; such as the process of inquirer, the number of witnesses, and the remaining cases in the court.

Asset specificity: From the research results, the asset specificity is not significant in the regression model equation. This can be explained by the strong correlation between the "Asset specificity" and the other three significant influencing variables: "Interdependence of activities", "Measurement problems", and "Uncertainty". Therefore, in the regression analysis, the "Asset specificity" does not have a statistically significant relationship with negative outcomes due to these relationships.

Small number of vendors: The reason for the insignificance for this factor is due to the fact that IT outsourcing market in Thailand is in growth stage according to the information from the expert in this field. In this stage, the establishment and expansion of customer database is very important to IT vendors' growth and sales volumes. Thus, IT outsourcing vendors intensify competition by doing whatever it takes to satisfy their customers in order to gain trustworthiness, brand awareness and first option in customer mind over their competitors. This refers to the influence and the importance of customers showing higher power of client rather than of vendors. This reduces the negative effect of the small number of vendors to the outsourcing companies in Thailand.

\section{CONCLUSION}

The research results in this study reveal the relationship between the risk factors and negative outcomes. This research has also discovered what type of influencing risk factors in the framework can significantly explain IT outsourcing negative outcomes. Four risk factors: "Measurement problem", "Lack of expertise of vendor with outsourced activity", "Uncertainty", and "Interdependence of activities", are significant predictors of negative outcomes in Thailand. The other risk factors: "Lack of expertise of client with outsourced activity", "Lack of expertise of client with outsourcing contract", "Lack of expertise of vendor with outsourcing contract", "Asset specificity", and "Small number of vendors" do not significantly affect negative outcomes but they can be specifically considered for a case-by-case study. By providing the IT outsourcing risk framework, this research can be used for minimizing the risk and maximizing the benefits of IT outsourcing. It will be a valuable contribution toward developing effective IT outsourcing risk management in Thailand in the future.

\section{ACKNOWLEDGMENT}

The authors would like to thank the reviewers for providing excellent feedback which the authors have taken as an input in order to improve the quality of this research paper. The authors would also like to thank Dr.Jesada Sivaraks and Ms.Wassana Kaewphanuekrungsi for their comments and suggestions on this paper. 


\section{REFERENCES}

[1] E. Turban, R. K. Rainer, and Potter, Introduction to Information Technology, New Jersey: John Wiley and Sons, 2004.

[2] I. Tho, Managing the Risks of IT Outsourcing, Oxford: Elsevier Butterworth-Heinemann, 2005.

[3] B. A. Aubert, M. Patry, and S. Rivard, "A framework for information technology outsourcing risk management," Database for Advances in Information Systems, vol. 36, issue 4, pp. 9-28, 2005.

[4] B. Bahli and S. Rivard, "The information technology outsourcing risk: A transaction cost and agency theory-based perspective," Journal of Information Technology, vol. 18, issue 3, pp. 211-221, 2003.

[5] K. Eisenhardt, "Agency theory: An assessment and review" Academy of Management Review, vol. 14, no. 1, pp. 57-74, 1989.

[6] B. A. Aubert, M. Patry, and S. Rivard, "A tale of two outsourcing contracts - An agency theoretical perspective," Economic of Computer Science, vol. 45, no. 2, pp. 181-190, 2003.

[7] O. E. Williamson, The Economic Institutions of Capitalism, New York: The Free Press, 1985.

[8] X.-H. Ke, "Primary research on the combination of english for computer course teaching and It outsourcing human resource pool," in Proc. of International Conference of Computer and Automation Engineering, 2010, vol. 4, pp. 472-475.

[9] B. Bahli and S. Rivard, "A validation of measures associated with the risk factors in information technology outsourcing," Proceedings of the 36th Annual Hawaii International Conference on System Sciences (HICSS'03), 2003.

[10] B. A. Aubert, M. Patry, and S. Rivard, "Assessing the risk of IT outsourcing," in Proc. Thirty-First Annual Hawaii International Conference on System Sciences, vol. 6, pp. 685-692, 1998.

[11] M. J. Earl, “The risks of outsourcing IT," Sloan Management Review, vol. 37, no. 3, pp. 26-32, 1996.

[12] M. C. Lacity, L. P. Willcocks, and D. F. Feeny, "IT outsourcing: Maximize flexibility and control," Harvard Business Review, vol. 73 , no. 3, pp. 84-93, 1995.

[13] M. C. Lacity and L. P. Willcocks, Global Information Technology Outsourcing: Search for Business Advantage, Chichester: John Wiley and Sons, 2001.

[14] S. J. Grossman and O. D. Hart, "The costs and benefits of ownership: A theory of vertical and lateral integration," Journal of Political Economy, vol. 94, no. 4, pp. 691-719, 1986.

[15] D. J. Teece, Firm boundaries, technological innovation and strategic management. in L. G. Thomas III (Eds.), The Economics of Strategic Planning, Lexington: Lexington Books, 1986.

[16] R. M. Wideman, "Risk management," Project Management Journal, pp. 20-26, September 1986.

[17] E. Van der Vliert, "Motivating effects of task and outcome interdependence in work teams," Group and Organisation Management, vol. 23, no. 2, pp.124-143, 1998.

[18] D. M. Wybo and L. D. Goodhue, "Using interdependence as a predictor of data standards: Theoretical and measurement issues," Information and Management, vol. 29, no. 6, pp. 317-329, 1995.

[19] P. Milgrom and J. Roberts, Economics, Organisation, and Management, New Jersey: Prentice-Hall, 1992.

[20] Y. Barzel, "Measurement cost and the organization of markets," Journal of Law and Economics, vol. 25, no. 1, pp. 27-48, 1982.

[21] S. Ang and L. Cummings, "Strategic response to institutional influences on information systems outsourcing," Organization Science, vol. 8, no. 3, pp. 235-256, 1997.

[22] K. Nam, S. Rajagopalan, H. R. Rao, and A. Chaudhury, "A two-level investigation of information systems outsourcing," Communications of the ACM, vol. 39, no. 7, pp. 37-44, 1996.
[23] G. Walker and D. A. Weber, "Transaction cost approach to make-or-buy decisions," Administrative Science Quarterly, vol. 29, no. 3, pp 373-391, 1984.

[24] B. K. Pilling, L. A. Crosby, and D. W. Jackson, "Relational bonds in industrial exchange: an experimental test of the transaction cost economic framework," Journal of Business Research, vol. 39, no. 3, pp. 237-251, 1994.

[25] M. C. Lacity and R. Hirschheim, Information Systems Outsourcing: Myths, Metaphors and Realities, Chichester: John Wiley and Sons, 1993.

[26] R. Klepper and O. W. Jones, Outsourcing Information Technology, Systems and Services, New Jersey: Prentice-Hall, 1998.

[27] U. Sekaran, Research Methods for Business: A Skill-Building Approach, NY: John Wiley and Sons, 2000.

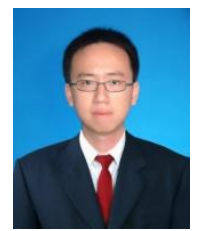

Thanapol Ongwattanasirikul was born on 1 September 1982 in Bangkok, Thailand. He received his Bachelor Degree in computer engineering in 2004 and completed his Masters Degree in management in 2007 from Mahidol University, Bangkok, Thailand.

From 2008 to 2010, he worked as an IT Consultant in PTT ICT Solutions Company Limited, Bangkok, Thailand. Since October 2010, he has been working in Siemens Group, Bangkok, Thailand as a Junior IC Consultant.

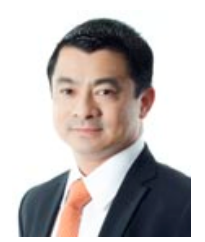

Settapong Malisuwan was born on 24th March 1966 in Bangkok, Thailand. He received his $\mathrm{PhD}$ in electrical engineering (telecommunications), specializing in mobile communication systems from Florida Atlantic University (State University System of Florida), Boca Raton in 2000. He received an MSc in electrical engineering in mobile communications system, from George Washington University in 1996, an MSc in electrical engineering in telecommunication engineering from Georgia Institute of Technology in 1992 and a BSc in electrical engineering from the Chulachomklao Royal Military Academy, Nakhon-Nayok, Thailand in 1990.

He served in the Royal Thai Armed Forces for more than 25 years and is currently the Vice Chairman of National Broadcasting and Telecommunications, Bangkok, Thailand. His research interests are in efficient spectrum management and Telecommunications policy and management in Thailand.

Col. Dr. Settapong Malisuwan Settapong Malisuwan is currently the Elected Vice Chairman and Board Member in the National Broadcasting and Telecommunications Commission, Thailand.

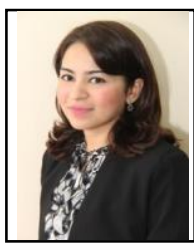

Navneet K. Madan was born in Bangkok, Thailand on 22nd April, 1987. She received her Bachelor of Business Administration in international business management from Mahidol University in 2008, and received Master of Science degree in strategic management and marketing, Middlesex university, London, United Kingdom. She has been working as an Assistant to Vice Chairman in National Broadcasting and Telecommunications, Bangkok, Thailand since January 2012. Her research interests are in Spectrum Management, Strategic Flexibility, Market Orientation and Environmental Uncertainty in Fast Clockspeed Industries. 